\title{
Cross-amplification and characterization of microsatellite loci for the Neotropical orchid genus Epidendrum
}

\author{
Fábio Pinheiro ${ }^{1,4}$, Clarisse Palma-Silva ${ }^{2}$, Fábio de Barros ${ }^{3}$ and Salvatore Cozzolino ${ }^{4}$ \\ ${ }^{1}$ Departamento de Botânica, Instituto de Biociências, Universidade de São Paulo, São Paulo, SP, Brazil. \\ ${ }^{2}$ Departamento de Botânica, Instituto de Biologia, Universidade Federal do Rio de Janeiro, \\ Rio de Janeiro, RJ, Brazil. \\ ${ }^{3}$ Instituto de Botânica, Seção de Orquidário do Estado, São Paulo, SP, Brazil. \\ ${ }^{4}$ Dipartimento di Biologia Strutturale e Funzionale, Complesso Universitario di Monte S. Angelo, \\ Università degli Studi di Napoli Federico II, Napoli, Italy.
}

\begin{abstract}
In this study we tested the cross-amplification of 33 microsatellite loci previously developed for two closely related Neotropical orchid genera (Epidendrum and Laelia). A set of ten loci were polymorphic across five examined species (20 individuals each) with 2 to 15 alleles per locus. The mean expected and observed heterozygosity (average across species) ranged from 0.34 to 0.82 and from 0.27 to 0.85 , respectively. In addition we tested all loci in 35 species representative of the genus Epidendrum. Of these, 26 loci showed successful amplification. Cross-application of these loci represent a potential source of co-dominant markers for evolutionary, ecological and conservation studies in this important orchid genus.
\end{abstract}

Key words: Epidendrum, Orchidaceae, short tandem repeat, cross-amplification.

Received: September 17, 2008; Accepted: November 18, 2008.

Epidendrum L. is the largest of the orchid genera in the Neotropical region, with approximately 1500 species (Hágsater and Arenas, 2005). Species of this genus display extensive variation in morphological features and growth habits (epiphytic, lithophytic and terrestrial). Moreover, they offer an interesting opportunity for exploring the influence of human activities on natural environments, since they occur within several types of threatened vegetation (Amazon and Atlantic Rainforests, savannas, coastal sand dunes, 'tepuis', and 'páramos').

Microsatellite markers are the current choice for most studies on evolution, ecology and conservation, due to their high levels of polymorphism and high reproducibility. Studies increasingly aim at comparing genetic, demographic, behavioural, and breeding system parameters among related species. To address these questions, researchers require 'universal' genetic markers that can easily be transferred between species (Barbara et al., 2007). The capacity to transfer and apply the same set of microsatellite loci in different species can significantly facilitate studies among closely related and endemic taxa. This is important where resources for undertaking conservational genetic studies are limited, thus making it less cost-effective to develop

Send correspondence to Fabio Pinheiro. Departamento de Botânica, Instituto de Biociências, Universidade de São Paulo, 05508900 São Paulo, SP, Brazil. E-mail: biopinheiro@yahoo.com.br. specific microsatellite loci for many species of the same taxa.

Although, positive cross-amplification of some microsatellite loci have been previously reported for a few species of Epidendrum (Cortés-Palomec et al., 2008; Pinheiro et al., 2008a, 2008b), to date, there is no precise and standardized information about amplification-efficiency or polymorphism in these loci. The aim of this study is to report the potential of cross-species transferability of microsatellite markers across the genus Epidendrum in order to identify a set of polymorphic loci available for inquiries assessing the effect of landscape fragmentation on gene flow, species delimitation, origin and the maintenance of reproductive barriers among species of this genus.

Total genomic DNA was extracted from silica gelexsiccated leaves according to the Pinheiro et al. (2008a) protocol. We tested three sets of microsatellite markers previously described for Epidendrum fulgens (nine loci - Pinheiro et al., 2008a), E. puniceoluteum (ten loci - Pinheiro et al., 2008b) and Laelia speciosa (14 loci - Cortés-Palomec et al., 2008), the latter a closely related genus belonging to the subtribe Laeliinae, the same subtribe as that of Epidendrum (Hágsater and Arenas, 2005). Altogether, we tested 33 microsatellite loci (Table S4) for cross-amplification in 35 species belonging to different sections of genus Epidendrum. 
For each microsatellite locus, the forward primers were synthesized with a $5^{\prime}$-M13 tail according to the Schuelke (2000) method, involving three primer polymerase chain reactions (PCRs), including a universal M13 primer labelled with a fluorescent dye, 6-FAM (Applied Biosystems). All PCR amplifications were performed in an Applied Biosystems 2700 thermocycler according to Pinheiro et al. (2008a, 2008b). The conditions were maintained constant for all loci so as to maximize standardization. Microsatellite alleles were resolved on a 3130 Genetic Analyzer (Applied Biosystems) and sized in accordance with LIZ (500) standard by using GENEMAPPER v. 3,7 software (Applied Biosystems).
We initially tested the potential of cross-amplification for all loci with one sample from each of the 35 Epidendrum species. Furthermore, we focused our effort on five of those species belonging to different phyletic sections of the genus Epidendrum (Hágsater and Arenas, 2005): E. denticulatum, E. secundum, E. campestre, E. densiflorum and E. rigidum. We sampled 20 individuals from each species of a single population (Table S1). GENEPOP software (Raymond and Rousset, 1995; web version 3.4) was used to calculate observed $\left(H_{\mathrm{O}}\right)$ and expected $\left(H_{\mathrm{E}}\right)$ heterozygosity, and to test for departure from Hardy - Weinberg equilibrium (HWE) as well as for link-

Table 1 - Size range of the PCR products, number of observed alleles (A), expected and observed heterozygosity $\left(H_{E} / H_{O}\right)$, and the significance of the test for departure from Hardy-Weinberg equilibrium, for the ten selected microsatellite loci (indicated by rows) in each of the five Epidendrum species. The size range of the original alleles described by the authors is indicated in parentheses below each locus.

\begin{tabular}{|c|c|c|c|c|}
\hline Locus & Species & size range & A & $H_{E} / H_{O}$ \\
\hline EPP08 & E. campestre & 211-219 & 3 & $0.19 / 0.20$ \\
\hline \multirow[t]{5}{*}{$(219-223)$} & E. densiflorum & $211-229$ & 5 & $0.71 / 0.36$ \\
\hline & E. denticulatum & $211-213$ & 2 & $0.51 / 1.00^{*}$ \\
\hline & E. rigidum & $201-215$ & 4 & $0.64 / 0.05^{*}$ \\
\hline & E. secundum & $213-221$ & 4 & $0.28 / 0.30$ \\
\hline & Mean & & 3.6 & $0.47 / 0.38$ \\
\hline EPP18 & E. campestre & $274-314$ & 11 & $0.88 / 0.89$ \\
\hline \multirow[t]{5}{*}{$(288-324)$} & E. densiflorum & $284-290$ & 3 & $0.68 / 0.70$ \\
\hline & E. denticulatum & $288-328$ & 15 & $0.92 / 0.84$ \\
\hline & E. rigidum & $284-312$ & 4 & $0.64 / 0.55$ \\
\hline & E. secundum & 284 & monomorphic & - \\
\hline & Mean & & 8.3 & $0.62 / 0.60$ \\
\hline EPP49 & E. campestre & $\begin{array}{c}\text { no ampli- } \\
\text { fication }\end{array}$ & - & - \\
\hline \multirow[t]{5}{*}{$(182-186)$} & E. densiflorum & $162-187$ & 9 & $0.79 / 0.32 *$ \\
\hline & E. denticulatum & $176-190$ & 6 & $0.78 / 0.70$ \\
\hline & E. rigidum & $170-186$ & 3 & $0.46 / 0.10$ \\
\hline & E. secundum & $176-186$ & 6 & $0.83 / 0.63$ \\
\hline & Mean & & 6 & $0.71 / 0.44$ \\
\hline EPP56 & E. campestre & $136-154$ & 3 & $0.14 / 0.10$ \\
\hline \multirow[t]{5}{*}{$(136-144)$} & E. densiflorum & $148-152$ & 2 & $0.10 / 0.10$ \\
\hline & E. denticulatum & $132-166$ & 10 & $0.87 / 0.85$ \\
\hline & E. rigidum & $152-156$ & 2 & $0.51 / 0.00^{*}$ \\
\hline & E. secundum & $122-162$ & 9 & $0.78 / 0.28 *$ \\
\hline & Mean & & 5.2 & $0.48 / 0.27$ \\
\hline EPP86 & E. campestre & $217-231$ & 8 & $0.83 / 0.85$ \\
\hline \multirow[t]{5}{*}{$(215-239)$} & E. densiflorum & $217-227$ & 6 & $0.81 / 0.80$ \\
\hline & E. denticulatum & $217-223$ & 4 & $0.71 / 0.60$ \\
\hline & E. rigidum & $217-235$ & 7 & $0.83 / 1.00 *$ \\
\hline & E. secundum & $215-229$ & 8 & $0.85 / 1.00$ \\
\hline & Mean & & 6.6 & $0.81 / 0.85$ \\
\hline
\end{tabular}

\begin{tabular}{|c|c|c|c|c|}
\hline Locus & Species & size range & A & $\mathrm{He} / \mathrm{Ho}$ \\
\hline EFF26 & E. campestre & $190-204$ & 8 & $0.76 / 0.84$ \\
\hline \multirow[t]{5}{*}{ (199-205) } & E. densiflorum & $196-202$ & 4 & $0.66 / 0.95$ \\
\hline & E. denticulatum & $164-202$ & 5 & $0.64 / 0.65$ \\
\hline & E. rigidum & $196-204$ & 5 & $0.66 / 0.75$ \\
\hline & E. secundum & $192-204$ & 6 & $0.77 / 0.88$ \\
\hline & Mean & & 5.6 & $0.70 / 0.81$ \\
\hline EFF45 & E. campestre & $280-284$ & 3 & $0.50 / 0.35$ \\
\hline \multirow[t]{5}{*}{$(288-294)$} & E. densiflorum & $288-294$ & 3 & $0.49 / 0.53$ \\
\hline & E. denticulatum & $278-294$ & 5 & $0.32 / 0.25$ \\
\hline & E. rigidum & $288-340$ & 5 & $0.81 / 0.35^{*}$ \\
\hline & E. secundum & $288-294$ & 4 & $0.67 / 0.55$ \\
\hline & Mean & & 4 & $0.56 / 0.41$ \\
\hline EFF58 & E. campestre & $210-212$ & 2 & $0.46 / 0.68$ \\
\hline \multirow[t]{5}{*}{$(210-212)$} & E. densiflorum & $210-216$ & 4 & $0.66 / 0.95$ \\
\hline & E. denticulatum & 212 & monomorphic & - \\
\hline & E. rigidum & $210-212$ & 2 & $0.51 / 1.00$ \\
\hline & E. secundum & 212 & monomorphic & - \\
\hline & Mean & & 2.7 & $0.34 / 0.54$ \\
\hline Lspe-1 & E. campestre & $219-221$ & 2 & $0.36 / 0.35$ \\
\hline \multirow[t]{5}{*}{$(350-390)$} & E. densiflorum & $215-225$ & 4 & $0.49 / 0.35$ \\
\hline & E. denticulatum & $471-493$ & 3 & $0.34 / 0.28$ \\
\hline & E. rigidum & $225-233$ & 2 & $0.49 / 0.00^{*}$ \\
\hline & E. secundum & $462-488$ & 9 & $0.85 / 0.85$ \\
\hline & Mean & & 4 & $0.51 / 0.37$ \\
\hline Lspe-3 & E. campestre & $250-266$ & 8 & $0.83 / 0.79$ \\
\hline \multirow[t]{5}{*}{$(224-250)$} & E. densiflorum & $250-288$ & 12 & $0.88 / 0.40^{*}$ \\
\hline & E. denticulatum & $262-304$ & 15 & $0.93 / 1.00$ \\
\hline & E. rigidum & $268-286$ & 5 & $0.78 / 0.25^{*}$ \\
\hline & E. secundum & $244-260$ & 6 & $0.69 / 0.90$ \\
\hline & Mean & & 9.2 & $0.82 / 0.67$ \\
\hline
\end{tabular}

Significant departures from HWE: ${ }^{*} \mathrm{p}<0.05$ 
age disequilibrium at each locus, by applying the Bonferroni correction to account for multiple comparisons.

Among the 33 loci tested, 26 showed positive amplification and PCR products with the expected allele sizes throughout most of the 35 species tested (Table S2). The percentage of cross-amplification was $78 \%$ on an average, thus higher than the mean value reported for monocot species $(60 \%$ - Barbara et al., 2007).

A total of ten polymorphic loci exhibited the features so desired for use as co-dominant molecular markers in the five examined species (Table 1), with the number of alleles per locus ranging from two to 15 (overall mean 5.6 alleles) Expected and observed heterozygosity ranged from 0.34 to 0.82 and 0.27 to 0.85 , respectively (an average of 0.60 and 0.53 , respectively) (Table 1). For each sampled population of the five species, we found sporadic cases of departure from HW equilibrium $(\mathrm{p}<0.05)$ : for loci EPP8 (in $E$. denticulatum and E. rigidum), EPP49 (in E. densiflorum), EPP56 (in E. rigidum and E. secundum), EPP86 (in $E$. rigidum), EFF45 (in E. rigidum), Lspe-1 (in E. rigidum) and Lspe-3 (in E. rigidum). Interestingly, six out of ten loci in E. rigidum departed significantly from $\mathrm{HW}$ equilibrium due to heterozygotic deficiency. Such deviations could be caused by inbreeding and/or Wahlund effects arising from secondary population subdivision. Although null alleles cannot be ruled out, there was no evidence of scoring error due to 'stuttering' or 'large allele dropout', when using MICRO-CHECKER software (van Oosterhout et al., 2004. Three loci in E. campestre, five loci in E. denticulatum, five loci in E. rigidum and seven in E. secundum exhibited linkage disequilibrium $(\mathrm{p}<0.001)$. Loci that were monomorphic or not amplified in most of the five Epidendrum species are listed in Table S3.

This study unveiled evidence that cross-transferability of developed microsatellite loci can increase the availability of markers to address both ecological and evolutionary questions in Epidendrum. The markers tested here showed to be of great potential for the use in comparing multiple co-occurring Epidendrum species in different ecological communities, thus contributing to knowledge on diversification processes and conservation among neotropical orchids.

\section{Acknowledgments}

This work was supported by grants from FAPESP (06/54189-3) and CNPq (471929/2006-9) to FP and FB, and by awards from CNPq and CAPES to FP and FB.

\section{References}

Barbara T, Palma-Silva C, Paggi GM, Bered F, Fay MF and Lexer C (2007) Cross-species transfer of nuclear microsatellite markers: Potential and limitations. Mol Ecol 16:3759-3767.
Cortés-Palomec AC, McCauley RA and Oyama K (2008) Isolation, characterization and cross-amplification of polymorphic microsatellite loci in Laelia speciosa (Orchidaceae). Mol Ecol Resour 8:135-138.

Hágsater E and Arenas MAS (2005) Epidendrum L. In: Pridgeon AM, Cribb P, Chase MW and Rasmussen FN (eds) Genera Orchidacearum. V. 4. Oxford University Press, Oxford, pp 236-251.

Pinheiro F, Santos MO, Barros F, Meyer D, Salatino A, Souza AP and Cozzolino S (2008a) Isolation and characterization of microsatellite loci in the Brazilian orchid Epidendrum fulgens. Conserv Genet 9:1661-1663.

Pinheiro F, Santos MO, Palma-Silva C, Barros F, Meyer D, Salatino A, Souza AP and Cozzolino S (2008b) Isolation and characterization of microsatellite loci in Epidendrum puniceoluteum, an endemic orchid from the Atlantic Rainforest. Mol Ecol Resour 8:1114-1116.

Schuelke M (2000) An economic method for the fluorescent labelling of PCR fragments. Nat Biotechnol 18:233-234.

\section{Internet Resources}

Raymond M and Rosset F (1995) Genepop: Population Genetics Software for Exact Test and Ecumenism. J Hered 86:248249. http://genepop.curtin.edu.au/ (September 15, 2008).

Van Oosterhout C, Hutchinson WF, Wills DPM and Shipley P (2004) MICRO-CHECKER: Software for Identifying and Correcting Genotyping Errors in Microsatellite Data. Mol Ecol Notes 4:535-538. http://www.microchecker.hull.ac.uk/ (September 15, 2008).

\section{Supplementary Material}

The following online material is available for this article:

Table S1 - Geographical region, sample size and Biome of species sampled.

Table S2 - Cross-species amplification of 26 loci tested for 30 additional Epidendrum species. Size range of the PCR products and unsuccessful amplifications are indicated (-).

Table S3 - Size range of the PCR products, number of observed alleles (A), expected heterozygosity (He), observed heterozigosity (Ho), and the significance of the test for departure from Hardy - Weinberg equilibrium (HWE Significant departures from HWE: $\mathrm{p}<0,001$ ), for the microsatellite loci (indicated by rows) that were not detected as polymorphic (monomorphic), or not amplified (na) in most of the five Epidendrum species. The size range of the original alleles described by the authors is indicated in parentheses on the bottom of each locus.

Table S4 - Primer names, sequences and Genbank Accession numbers of 33 orchid species SSR loci.

\section{Associate Editor: Everaldo Gonçalves de Barros}

License information: This is an open-access article distributed under the terms of the Creative Commons Attribution License, which permits unrestricted use, distribution, and reproduction in any medium, provided the original work is properly cited. 